\title{
Chemical relaxers and curlers: Hidden danger
}

\author{
Smriti Vyas ${ }^{1}$, Kalpana Gupta ${ }^{2, *}$, Parth Modi ${ }^{3}$, Ankit Bhadee ${ }^{4}$ \\ ${ }^{1}$ 3rd year Resident, ${ }^{2}$ Professor \& HOD, ${ }^{3}$ Resident, ${ }^{4}$ Lawyer, ${ }^{1-3}$ Dept. of Skin and VD, Geetanjali Medical College and Hospital, \\ Udaipur, Rajasthan, ${ }^{4}$ Rajasthan High Court, Jaipur, Rajasthan, India
}

*Corresponding Author:

Email: smriti.sv.91@gmail.com

\begin{abstract}
Introduction: Hair is the most noticeable part of one's beauty and enhances individual's personality. Hair loss is largely the result of genetics and hormones, however, lifestyle (hair colouring, fashion etc.) and environmental factors such as hair styling, eating habits and chemical exposure has major role. As more women are embracing their natural hair by exposing them to chemical relaxers resulting in an untold havoc with our physical health.

Aims and Objectives: To examine the patients undergoing repeated chemical relaxing and curling

Methodology: A cross-sectional observational hospital based study was carried out on purposively selected patients diagnosed with telogen effluvium. Forty seven patients of either sex, aged between 18 to 50 yrs those who had undergone relaxing and curling more than once over a period of 12 months

Result: Out of 47 patients diagnosed to have hair fall, 13 were male and 34 were female. $49 \%$ belonged to the age group of $25-31$ years. $42 \%$ of patients applied relaxers up to 4 times while $7 \%$ used up to 10 times. The commonest adverse events associated with the use of chemical hair relaxers were hair loss (61\%), dry hair (45\%), dandruff (20\%), thinning of hair (30\%), greying of hair $(25 \%)$ and split ends in only (15\%).

Conclusion: Hair fall, lack of hair growth, hair breakage, hair thinning, scalp irritation are the main adverse effects faced due to the continuous use of hair relaxers and curlers. However, chemical hair relaxers have been know to cause adverse effects is not a false belief and affected the society badly. Therefore one should be very careful while using and applying any sort of chemical to your hairs.
\end{abstract}

Keywords: Chemical Hair Relaxers, Falling of Hair, Hair loss, Scalp Irritation, Hair Breakage.

\section{Introduction}

Hair is the most noticeable part of one's beauty and enhances individual's personality. Personal image, as it relates to external beauty, has attracted much attention from the cosmetic industry, and capillary aesthetics is a leader in consumption in this $\operatorname{area}^{2}$. Hair loss is largely the result of genetics and hormones, however, lifestyle (hair colouring, fashion etc.) and environmental factors such as hair styling, eating habits and chemical exposure has major role. Some methods of hair styling are universally damaging to the hair but usually when they are stopped, the affected part grows back ${ }^{1}$. Most of the women in India are using hair styling products for beautification purpose and to look young and attractive which exposes them to a lot of harsh chemicals making the hairs shaft weak making them easily liable to break.

African women are more indulge in usage of hair styling and straightening products to straighten their curly hairs. ${ }^{7}$ Hair relaxers can cause folliculitis, scalp problems, along with fibroids and tumors due to entry of toxic ingredients into the body. ${ }^{8-15}$

In current scenario, usage of chemical relaxers are very common in our society. ${ }^{1}$ During the chemical process, the natural sulfide bonds of hairs are broken and converted into a straight, relaxed pattern.

The chemicals used in the process -- lithium hydroxide, guanidine hydroxide and sodium hydroxide are generally safe if used properly. Improper use by an unethical and unprofessional person results into scalp burns, infections, damage, breakage and hair loss. Historically, they were mainly used by AfricanAmerican women to straighten their curly hair and easy management. $^{5}$

Hair relaxers are divided into two types: "Lye" relaxers, no-lye relaxers and "thio" relaxers. ${ }^{6}$

An observational questionnaire based study of the adverse events recorded by a sample from repeated application of chemical hair relaxers.

\section{Aims and Objectives}

To examine the patients undergoing repeated chemical relaxing and curling.

\section{Materials and Methods}

A cross-sectional observational hospital based study was carried out on purposively selected patients diagnosed with telogen effluvium. The sample included those patients who had undergone relaxing and curling more than once over a period of 12 months. Patients visiting outdoor of Department of Skin, Venereology and Dermatology of Geetanjali Medical College and Hospital, Udaipur (Raj.) between the period of six months ( $15^{\text {th }}$ January 2017 to $15^{\text {th }}$ July 2017 ).

To access the opinion and the outcome of chemical relaxers a set of question based survey was prepared to collect demographic data, reason for straightening, and various adverse events occured. The questionnaire was 
got filled by 100 parturient, out of which 47 matched our criteria.

\section{Inclusion Criteria:}

a. Patients aged 18 to $50 \mathrm{yrs}$.

b. Willing to participate and give written informed consent.

c. Those who underwent relaxing more than once.

\section{Exclusion Criteria:}

a. Those not willing to give consent.

b. On any major dermatological treatment (including steroids) or hair transplant.

c. Having any other major medical, surgical or psychiatric illness.

d. Samples with prior history of hair loss and scalp disease.

\section{Data analysis}

Parturient were assessed according to sex. They were divided into age groups of 18 to 24 yrs, 25 to 31 yrs, $32-38$ yrs, 39 to 45 yrs and 46 to 50 yrs. Multiple applications of relaxers was noted. Frequency and percentage of maximum time of chemical application used with reasons of using them were calculated and tabulated.

\section{Results}

The present study comprised of 47 patients diagnosed to have hair fall out of which 13 were male and 34 were female. The data showed maximum number of patients $(48.94 \%)$ belonged to the age group of 25-31 years, followed by $23.40 \%$ of $18-24$ yrs, $19.15 \%$ of $32-38 \mathrm{yrs}$ and $8.51 \%$ of $39-45 \mathrm{yrs}$, who have used repeated chemical relaxing and curling. None were between $46-50$ yrs of age (Fig. 1).

$27(57.44 \%)$ number of the participants used the chemical relaxers for the need of beautification of the face and hair, $8(17.02 \%)$ have used them for the ease of hair management, 7 (14.89\%) for the peer pressure and $5(10.64 \%)$ for the social acceptability (Fig. 2).

Highest frequency of use of chemical relaxers was $42.55 \%$ (20) for five times, $27.65 \%$ (13) for 3 times, $23.40 \%^{11}$ for twice and the least were $6.38 \%$ who used upto 10 times (Table 1).

In our study, out of 13 males and 34 females, 18 females and 9 males had the most common adverse events associated with the use of relaxers as hair loss. 12 females had complaint of dry hair, 8 had breakage of hair, 7 had greying of hair, 4 had dandruff and 4 had split ends. Whereas 9 males had complaint of frizzy hairs, followed by thinning of hair, dandruff, graying and split ends in 6, 5, 5 and 3 persons respectively (Fig. $3)$.

\section{Discussion}

Chemical hair straightening is a process of changing naturally curly or kinky hair to permanent straight hair using chemical agents. Chemical relaxers used on the hair contain sodium, potassium, or guanine hydroxides, sulfites, or thioglycolates. ${ }^{5}$ All these chemicals work to give a straighten look of hair by breaking the disulfide bonds of the hair. This weakens the portion hair, as the dislocation of disulfide bonds occurs only by structural damage to the shaft which decreases the tensile strength compared to untreated hair. ${ }^{20}$ Earlier straightening of hair was achieved by alkaline de-arrangement of the disulphide bonds in the cortex of the hair shaft ${ }^{16}$. Because of the high $\mathrm{pH}$ of the chemicals used, the process leaves the hair dry, weak and fragile. ${ }^{17}$

The present study comprised of 13 males and 34 females, a total of 47 patients. Maximum of them were fashionable youngsters, $48.94 \%$ were in the age group of 25-31 years, followed by $23.40 \%$ of $18-24$ yrs.

These finding had similarities with the studies done by Shetty $\mathrm{VH}^{1}$ and Swee $\mathrm{W}^{16}$ in which they found $95 \%$ of their subjects had hair loss and hair breakage. The difference could be due to the type of the chemical used and the frequency of procedure done. In our study $57.44 \%$ of the participants used the chemical relaxers for the need of beautification of the face and hair, 8 $(17.02 \%)$ have used them for the ease of hair management.

The most prevalent of hair change found in our study was graying of hair seen in $25.53 \%$ of the samples, which was quite similar to findings those of Shetty $\mathrm{VH}^{1}$. Whereas in a study carried out by Swee W hair were coloured green, red, orange, or yellowish hue.

Highest frequency of use of chemical relaxers was $42.55 \%$ (20) for five times, $27.65 \%$ (13) for 3 times, $23.40 \%$ (11) for twice and the least were $6.38 \%$ (3) who used upto 10 times.

Hair breakage, hair thinning, lack of hair growth, scalp irritation, scalp damage, hair loss are some of the complaints from many who experience problems due to the misuse or chronic use of chemical hair relaxers. ${ }^{5,21}$

In our study, 18 females and 9 males had the most common complaint of hair loss. 12 females had complaint of frizzy hair, 8 had thinning and breakage of hair, 7 had graying of hair, 4 had dandruff and 4 had split ends. Whereas 9 males had complaint of frizzy hairs, followed by thinning of hair, dandruff, graying and split ends in 6, 5, 5 and 3 persons respectively (Fig. 3).

In our study we found split ends $6.38 \%$ were found to be an side-effect which is very rarely reported. Another study by Shetty $\mathrm{VH}^{1}$ reported $15 \%$, of such averse side-effect of split end hair. They have been stated that long term use of such products can be harmful as it is believed to enter the scalp through scalp lesions and burns. ${ }^{1}$ Irritant contact dermatitis after the use of chemical hair relaxers was reported in woman by Kaur et al. ${ }^{19}$ Loss of skin integrity as a consequence of trauma, burns, maceration, eczema etc. predispose to local skin colonization with chemical relaxers and subsequent infection. ${ }^{18}$ Localized skin and soft tissue 
infections caused by chemical relaxers are common and can manifest in several ways. ${ }^{19}$

Seeing all this side-effects in the study it is clear that there are very few serious adverse effects associated with chemical relaxers, however, there exists a correlation between hair relaxers and adverse reactions to the regular use.

\section{Chart 1: Distribution of patients according to age group and Hair Fall}

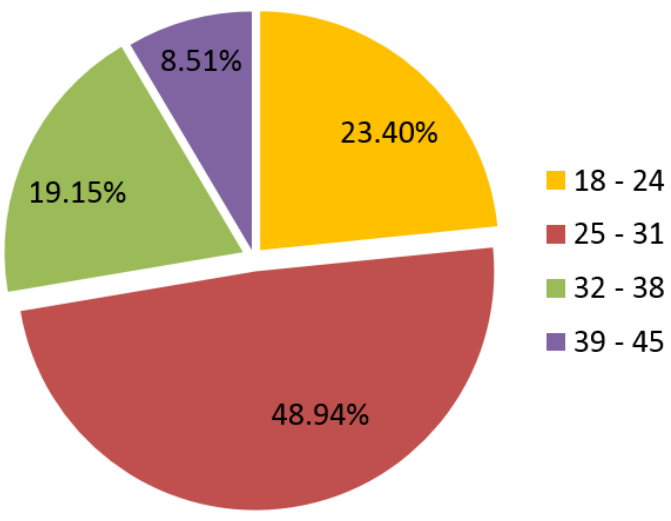

Fig. 1: Frizzy or dry hair

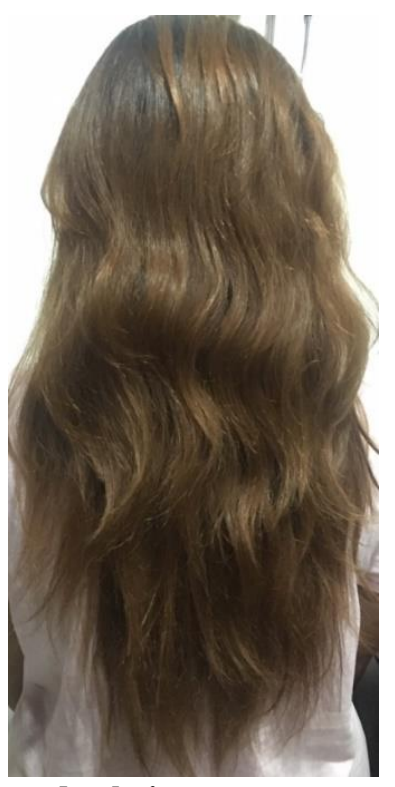

Chart 2: Reasons for undergoing the procedure

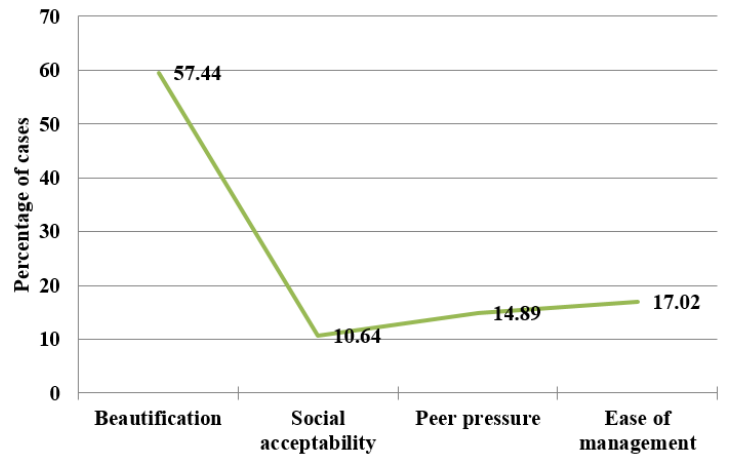

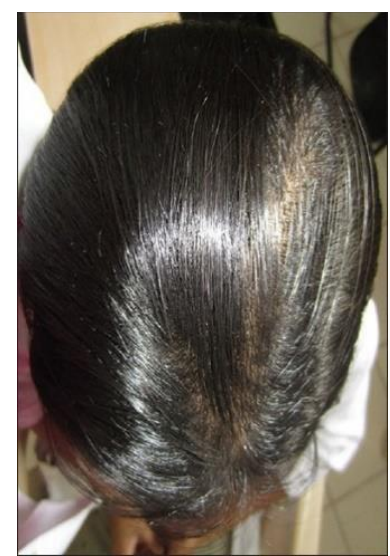

Fig. 2: Hair loss over the center of the scalp

Table 1: Usage of Chemical Relaxers

\begin{tabular}{|c|c|c|}
\hline Number of times & No. & Percentage \\
\hline 2 & 11 & 23.40 \\
\hline 3 & 13 & 27.65 \\
\hline 5 & 20 & 42.55 \\
\hline 10 & 3 & 6.38 \\
\hline
\end{tabular}

Chart 3: Genderwise general complaints
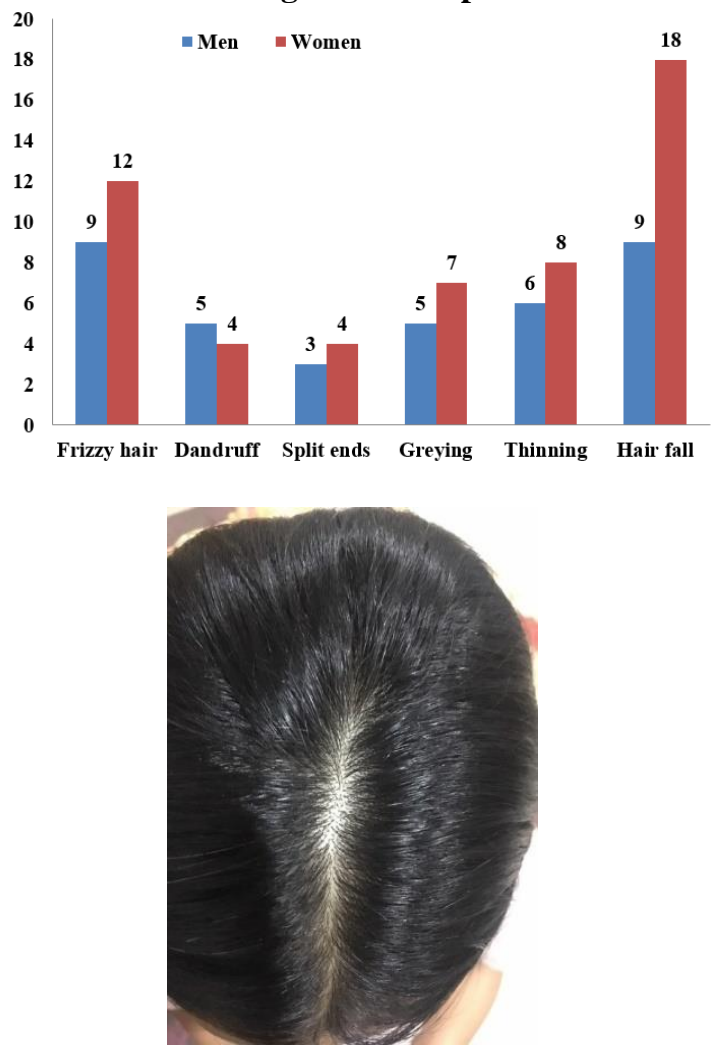

Fig. 3: Widening of central partition with frizzy hair 


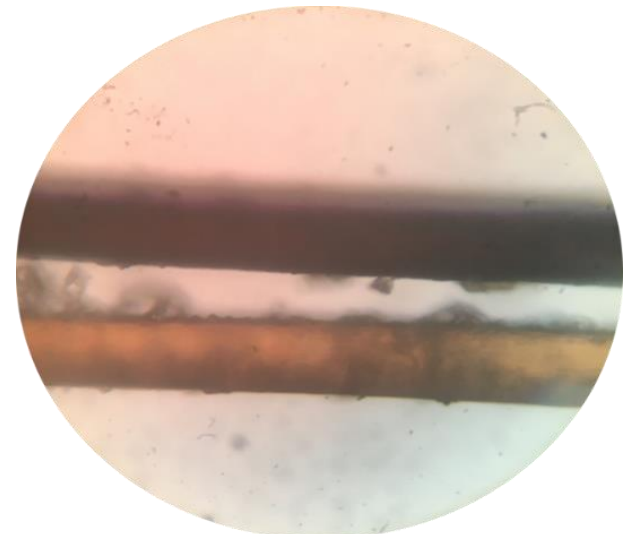

Fig. 4: Microscopic view showing difference between normal and chemically relaxed hair

\section{Conclusion}

Hair breakage, hair thinning, lack of hair growth, scalp irritation, damage, hair loss, these are just some of the complaints from many who experience problems due to the misuse of chemical hair relaxers. Yet in so many stores around the country, chemicals are available for everyone to use, without much instruction. Before beginning any hair treatment, especially one that introduces chemicals to your hair, you owe it to yourself to be well informed. In general, the more sodium hydroxide used and the higher the $\mathrm{pH}$, the quicker the chemical reaction will take place on the hair, and the greater the danger will be of hair damage.

Body image and self-esteem are not negotiable especially in youngsters who need corporate appearance to make an impression in their places of work. However, great care should be taken in the use of chemical hair relaxers.

Funding: No funding sources.

Conflict of interest: None declared.

\section{References}

1. Shetty VH, Shetty NJ, Nair DG. Chemical Hair Relaxers Have Adverse Effects a Myth or Reality. Int J Trichology 2013;5:26-8.

2. Miranda-Vilela AL, Botelho A de J, Muehlmann L A, An overview of chemical straightening of human hair: Technical aspects, potential risks to hair fibre and health and legal issues. (Pubmed) 2013;10:66-8.

3. NP. Khumalo, J Stone, F Gumedze, E McGrath, M R. Ngwanya, D de Berker. 'Relaxers' damage hair:
Evidence from amino acid analysis. jaad.org 2010; 62: 402-408.

4. BA. Etemesi. Impact of hair relaxers in women in Nakuru, Kenya. Int J Dermatol 2007; 10: 23-25.

5. Olasode OA. Chemical hair relaxation and adverse outcomes among Negroid women in South West Nigeria. J Pak Assoc Dermatol 2009; 19: 203-7.

6. Rosenberg L, Boggs DA, Adams-Campbell LL, Palmer JR. Hair relaxers not associated with breast cancer risk: Evidence from the black women' health study. Cancer Epidemiol Biomarkers Prev 2007;16:1035-37.

7. de Sa' Dias TC, Baby AR, Kaneko TM, et al. Relaxing/ straightening of Afro-ethnic hair: historical overview. $J$ Cosmet Dermatol 2007;6(1):2-5.

8. Halder RM. Hair and scalp disorders in blacks. Cutis 1983;32(4):378-80.

9. Scott DA. Disorders of the hair and scalp in blacks. Dermatol Clin 1988;6(3):387-95.

10. Dogra A,Minocha YC, Kaur S. Adverse reactions to cosmetics. Indian J Dermatol Venereol Leprol 2003;69(2):165-67.

11. Gendler E. Adverse reactions to cosmetics. Cutis 1987;39(6):525-26.

12. Menkart J. An analysis of adverse reactions to cosmetics. Cutis 1979;24(6):599-662.

13. Nigam PK. Adverse reactions to cosmetics and methods of testing. Indian J Dermatol Venereol Leprol 2009;75(1):10-8.

14. Harris RT. Hair relaxing. Cosmet Toilet 1979;94:51-6.

15. Seizure Action Initiated Against "Rio Naturalizer" Hair Products [press release]. Rockville, MD: Food and Drug Administration 1995:95-103.

16. Swee W, Klontz KC, Lambert LA. A nationwide outbreak of alopecia associated with the use of a hairrelaxing formulation. Arch Dermatol 2000;136:1104-8.

17. Dias TC, Baby AR, Kaneko TM, Velasco MV. Protective effect of conditioning agents on Afro-ethnic hair chemically treated with thioglycolate-based straightening emulsion. J Cosmet Dermatol 2008;7:120-26.

18. Hill MK, Sainders CV. Skin and soft tissue infections in critical care. Ciit Care Clin 1998;14:251-62.

19. Kaur Birinder J., Harmeet Singh, and Alan LinGreenberg. Irritant contact dermatitis complicated by deep-seated staphylococcal infection caused by a hair relaxer. J Natl Med Assoc 2002;94:121-23.

20. Khalil EN. Cosmetic and hair treatments for the black consumer. Cosmet Toil 1986;101:51-8.

21. Dowing JG. Dangers involved in dyes, cosmetics and permanent wave lotions applied to hair and scalp. Arch Dermatol 1951;63:561.

How to cite this article: Vyas S., Gupta K., Modi P., Bhadee A. Chemical relaxers and curlers: Hidden danger. Indian J Clin Exp Dermatol 2018;4(4):331-34. 